\title{
Too many, too fast? Dynamics of net migration in OECD, 1984-2001
}

\author{
Nikolay Zubanov \\ Birmingham Business School, University of Birmingham, Edgbaston, \\ Birmingham B15 2TT, UK \\ E-mail:n.zubanov@bham.ac.uk
}

A dynamic model of migration developed by Hatton (1995) has been applied to the panel of 23 OECD countries observed during 1984-2001. Migration flows have been found to have a tendency to overreact to changes in economic conditions. Thus, simulations have shown that in the Anglo-American group of countries (Australia, Canada, Ireland, UK and USA) a given relative improvement in economic circumstances which brings an extra 0.840 immigrants per 1000 population per year (334800 in total) in the short run, brings somewhat fewer (288 700 in total) in the long-run.

\section{Introduction}

This article starts from the position that migration decisions are dynamic. It applies Hatton's (1995) model in which individuals maximize their lifetime utility given the expected benefits and costs of moving based on past observations. Dynamics in migration flows may have important policy implications. It has been observed (Camarota, 2004) that when the US economic growth slowed down in early 2000s, immigration did not fall immediately to its predicted level but remained close to its pre-recession level for some time. This phenomenon could be explained by migration flows' exhibiting some inertia. ${ }^{1}$ However, apart from anecdotal facts reported in Camarota (2004), there is no compelling theoretical argument and little modern evidence on the direction of this adjustment.
To answer this question empirically, we apply Hatton's model to a panel of 23 OECD countries observed during 1984-2001. The dependent variable is the net migration rate calculated according to Eurostat's (2004) methodology. ${ }^{2}$ The covariates include a selection of variables used in previous studies on the topic (Hatton and Williamson, 1998, 2002, 2003; Rotte and Vogler, 1998; Clark et al., 2002; Fertig, 2001; Pedersen et al., 2004; Mayda, 2004), such as relative income, employment opportunities, immigrant population and demographic variables. We find that migration indeed tends to overreact to changes in economic conditions. Implementing the scenario of a simultaneous change in relative income, employment, labour force participation and lagged birth rate, we receive that short-run changes in net migration rate are in most cases larger than their long-run counterparts.

\footnotetext{
${ }^{1}$ For anecdotal evidence see, for instance, The Economist, 'Half a Billion Americans?', 22 August 2002; The Economist, 'Where The East Europeans Go?', 24 February 2005.

${ }^{2}$ The net migration rate is estimated using aggregate population data, as the difference between the total population growth and the natural population growth (the birth rate net of the death rate). This standard method avoids inconsistencies in migration accounting in different countries.
} 


\section{The Model and Data}

Hatton's (1995) model results in an error-correction process for migration, where the current change in net migration rate in country $i$ at time $t$ is affected both by its own lag and current changes and lags of the explanatory variables. We estimate this model on a panel of 23 OECD countries over the years 1984-2001. Definitions and basic summary statistics for the equation variables are given in Table 1 . The descriptive statistics show that our sample consists of relatively wealthy, urbanized and open to trade countries with noticeable presence of foreign population and sizeable net immigration. As expected, the majority of our variables are nonstationary, which issue we address in designing the estimation procedure below.

The estimation proceeds in two steps. First, the long-run equilibrium level of the net migration rate, $n e t_{i 1}^{*}$, is expressed as

$$
\begin{aligned}
& \text { net }_{i t}^{*}=a_{i 1} \text { grelworld }_{i t}+a_{i 2} \text { erel }_{i t}+a_{i 3} \text { foreign }_{i t} \\
& +a_{i 4} \text { urban }_{i t}+a_{i 5} \text { trade }_{i t}+a_{i 6} \text { labrel }_{i t} \\
& +a_{i 7} b r 20_{i t}+a_{i 8} t+\mu_{i}+\tau_{t}
\end{aligned}
$$

Adding the short-run dynamics part,

$$
\begin{aligned}
S_{i t}= & b_{i 1} \Delta \text { grelworld }_{i t}+b_{i 2} \Delta_{\text {erel }_{i t}}+b_{i 3} \Delta \text { foreign }_{i t} \\
& +b_{i 4} \Delta \text { urban }_{i t}+b_{i 5} \Delta \text { trade }_{i t}+b_{i 6} \Delta \text { labrel }_{i t} \\
& +b_{i 7} \Delta{\text { br } 20_{i t}}
\end{aligned}
$$

we obtain:

$$
\begin{aligned}
& \Delta n e t_{i t}=S_{i t}+\gamma_{i} \cdot\left(\text { net }_{i t} 1-n t_{i t}^{*} 1\right)+\varepsilon_{i t}, \\
& i=1, \ldots, N, t=1, \ldots, T
\end{aligned}
$$

Here $N$ is the number of countries; $T$ is the number of years; $\gamma_{i}$ is the error correction coefficient that represents the speed of adjustment of the actual value of net to its long-run equilibrium (1) within one period, since the departure from it; $\mu_{i}$ and $\tau_{t}$ are, respectively, country- and time-specific fixed effects; and $\varepsilon_{i t}$ is a stochastic error following the usual assumptions.

As can be seen from (2) and (3), we do not impose the slope coefficient equality restriction in the beginning, which comes at the expense of having to estimate a great many of country-specific parameters. To make the task feasible, we estimate (1) first, and then continue with the main Equation 3 using the residuals from (1). This option implies certain restrictions on combinations of estimated coefficients of Equations 1 and 3 to be valid. ${ }^{3}$ To make the model parsimonious yet not losing the informative variety of slope coefficients, we test their equality within the following groups of countries:

Group 1 - Continental Europe: Austria, Belgium, France, Germany, Luxembourg, Netherlands and Switzerland;

Group 2 - Southern Europe: Greece, Italy, Portugal and Spain;

Group 3 - Anglo-American countries: Australia, Canada, Ireland, UK and USA;

Group 4 - Asia: Japan, Korea and Singapore;

Group 5 - Northern Europe: Denmark, Finland, Norway and Sweden.

To avoid the spurious regression problem which may be caused by some variables being nonstationary (Table 1), we deal with them first. To find a stationary linear combination of grel, foreign, urban, trade and labrel, we estimate:

$$
\begin{aligned}
\text { grelworld }_{i t}= & c_{1 i} \text { foreign }_{i t}+c_{2 i} \text { urban }_{i t}+c_{3 i} \text { trade }_{i t} \\
& +c_{4 i} \text { labrel }_{i t}+c_{5 i} t+v_{i t}
\end{aligned}
$$

where $v_{i t}=c_{0 i}+w_{i t}$ is the error term, $c_{0 i}-$ fixed effect, $\quad w_{i t} \sim N\left(0, \omega_{i}^{2} I_{N T}\right)$. We have found $w_{i t}$

${ }^{3}$ To see this, consider estimation of an error correction model with two explanatory variables:

$$
\Delta z_{t}=a \Delta x_{t}+b \Delta y_{t}+\gamma\left(z_{t-1} \quad c x_{t-1} \quad g y_{t-1}\right)+\varepsilon_{t}
$$

The usual way of estimating it is converting it into a linear auto regressive distributed lag (ADL) model,

$$
z_{t}=h z_{t-1}+k x_{t}+m x_{t-1}+n y_{t}+p y_{t-1}+u_{t}
$$

and apply a consistent estimator to it. Then one could reparameterize the estimated ADL into an ECM:

$$
\Delta z_{t}=k \Delta x_{t}+n \Delta y_{t}+\left(\begin{array}{ll}
h & 1
\end{array}\right)\left(z_{t-1}+\frac{m+k}{h \quad 1} x_{t-1}+\frac{p+n}{h \quad 1} y_{t-1}\right)+u_{t}
$$

If, however, one proceeds by estimating

$$
z_{t-1}=c x_{t-1}+g y_{t-1}+e_{t}
$$

and then the original error correction model with the residuals from (iii) in it, the implicit assumption is that the respective coefficients in (i) and (ii) should be equal. There is no problem with it, at least from the point of view of econometric theory, when variables are nonstationary in levels, as any correlation between the differences and levels of nonstationary variables can only be spurious. Therefore, estimating Equation iii separately will not produce systematically biased slope coefficients. 
Table 1. Descriptive statistics

\begin{tabular}{|c|c|c|c|c|}
\hline Variable & Definition & Mean & SD & Stationary \\
\hline net & Annual net migration rate, persons per 1000 of population & 2.83 & 4.59 & Yes \\
\hline foreign & Share of foreign population $(\%)$ & 7.34 & 7.74 & No \\
\hline grelworld & Log ratio of country per capita income and world average & 1.49 & 0.43 & No \\
\hline erel & Relative employment rate: country less OECD average $(\%)$ & 0.13 & 3.74 & Yes \\
\hline urban & Share of urban population $(\%)$ & 76.44 & 12.86 & No \\
\hline trade & Trade to GDP ratio $(\%)$ & 80.60 & 58.26 & No \\
\hline labrel & Relative labour force participation rate: country less world average $(\%)$ & 0.30 & 4.60 & No \\
\hline br20 & Birth rate lagged 20 years & 16.62 & 4.14 & Yes \\
\hline
\end{tabular}

Source: The World Bank World Development Indicators database, OECD Economic Outlook (various issues), own calculations.

Notes: Stationarity has been tested using a selection of panel data unit root tests: LL Levin and Lin, BM Breitung and Meyer, IPS Im, Pesaran and Shin tests.

stationary and put it into the long-run equilibrium (Equation 1) instead of all the nonstationary variables:

$$
n e t_{i t}=b_{i 1} \text { erel }_{i t}+b_{i 2} b r 20_{i t}+b_{i 3} \hat{w}_{i t}+\eta_{i t}
$$

The short-run dynamics part (2) of the main Equation 3 is estimated at the final stage, using the residuals from (5) lagged by one period to represent the error-correction mechanism. We apply the fixed-effects estimator. Restrictions of cross-country equality of slope coefficients are tested at every stage of estimation and found not to hold, which supports our approach of treating the country groups separately.

\section{Estimation Results}

To save space, in Table 2 we only report coefficients on the main variables in our study: relative income (grelworld), employment (erel), labour force participation (labrel), 20-year lagged birth rate (br20), and the error correction term $(\gamma)$ for all countries studied. ${ }^{4}$ As can be seen, higher income and employment opportunities attract immigration, while demographic pressure (proxied by $b r 20$ ) deters it. These findings are in line with the literature.

The focus of this study, however, is on the error-correction coefficient, $\gamma$, which shows the share of the difference between actual and equilibrium levels of net immigration reduced by a 1 -year change in the net migration rate. Around 37\% of the difference between actual and equilibrium levels of net immigration is eliminated per year in the countries of groups 1, 3 and 5; and around $87 \%$ in the countries of groups 2 and 4 . These differences in the speed of adjustment to equilibrium between countries show diversity of individual countries' experiences of economic migrations. In the group 1 , 3 and 5 countries featuring slower speed of adjustment it takes longer until a predicted outcome is observed, since it is harder to combat the inertia in migration flows. Therefore, declaring a migration policy failure in a 'slower-adjusting' country on the basis of observing a success of a similar policy in a 'faster-adjusting' one may be premature, since it might be the case that not enough adjustment has yet occurred.

\section{Short- to Long-run Adjustment of Net Migration Rates: A Simulation}

To gauge the differences between short- and long-term consequences of a given stimulus for migration, we simulate the results of a given scenario (see Clark et al., 2002 for a similar study). The scenario we have chosen assumes a simultaneous one-off one-SD increase in relative income, employment and labour force participation, and a decrease in the lagged birth rate. These developments have been observed in most of the countries in our sample for the last few decades.

Simulation results are reported in Table 3. The difference between predicted short- and long-run effects of the chosen scenario on the net migration rate is systematically positive (with only two exceptions, Australia and Portugal), which suggests that immigrants overreact to changes in the economic environment at the destination country. This is an unexpected finding, given that migration costs can postpone a decision to move countries, even if income differences create an incentive to move now. On the other hand, admitting a possibility to

\footnotetext{
${ }^{4}$ Full set of results is available from the author.
} 
Table 2. Estimation results for Equations 1-3

\begin{tabular}{|c|c|c|c|c|c|c|c|c|c|c|}
\hline \multirow[b]{2}{*}{ Group } & \multirow[b]{2}{*}{ Country } & \multicolumn{2}{|l|}{ grelworld } & \multicolumn{2}{|l|}{ erel } & \multicolumn{2}{|l|}{ labrel } & \multicolumn{2}{|l|}{ br20 } & \multirow[b]{2}{*}{$\gamma$} \\
\hline & & (1) & (2) & (1) & (2) & (1) & (2) & (1) & (2) & \\
\hline 1 & $\begin{array}{l}\text { Austria } \\
\text { Belgium } \\
\text { France } \\
\text { Germany } \\
\text { Luxembourg } \\
\text { Netherlands } \\
\text { Switzerland }\end{array}$ & 20.538 & & 0.199 & 0.252 & 1.665 & & & 0.16 & -0.373 \\
\hline 2 & $\begin{array}{l}\text { Greece } \\
\text { Italy } \\
\text { Portugal } \\
\text { Spain }\end{array}$ & 45.821 & & 0.856 & 0.287 & 11.017 & & & $\begin{array}{r}0.963 \\
0.188 \\
-\mathbf{1 . 3 2 5}\end{array}$ & -0.872 \\
\hline 3 & $\begin{array}{l}\text { Australia } \\
\text { Canada } \\
\text { Ireland } \\
\text { UK } \\
\text { US }\end{array}$ & 20.538 & 15.574 & 0.199 & 1.139 & 1.665 & $\mathrm{~N} / \mathrm{A}$ & -0.573 & $\begin{array}{l}0.188 \\
\mathbf{0 . 9 6 3}\end{array}$ & -0.373 \\
\hline 4 & $\begin{array}{l}\text { Japan } \\
\text { Korea } \\
\text { Singapore }\end{array}$ & 162.069 & & 1.529 & & 11.017 & & & $\begin{array}{r}0.188 \\
-\mathbf{1 . 3 2 5}\end{array}$ & -0.872 \\
\hline 5 & $\begin{array}{l}\text { Denmark } \\
\text { Finland } \\
\text { Norway } \\
\text { Sweden }\end{array}$ & 20.538 & & 0.199 & 0.252 & 1.665 & & & 0.16 & -0.373 \\
\hline
\end{tabular}

Notes: Variables significant at 5\% are highlighted in bold; at 10\% italicised. Columns (1) and (2) report short and long run impacts, respectively. Separate long run estimate for labrel is not available, as being a nonstationary variable it has been included in a cointegrating Equation 4 with grelworld.

re-emigrate at some point allows for this effect to happen. Thus, the short-run wave of immigrants would gradually retreat due to difficulties in finding employment, inability to assimilate, restrictive immigration policy or genuine wish to return home having earned some income abroad, thus reducing migration pressure in the long-run.

This short- to long-run adjustment dynamics of migration imply that policy makers in migrant destination countries would observe more immigrants coming shortly after an improvement in economic conditions than the number based on long-run predictions. Thus, our group-wide estimations for the Anglo-American countries (group 3) show that a simultaneous one-SD increase in relative income, employment and labour force participation and a one-SD drop in the lagged birth rate would result in an extra 0.840 immigrants per 1000 population per year (334800 persons in total) in the short-run, and 0.725 per 1000 population per year (288 700 persons in total) in the long-run. This difference between the current net migration rate and its long-run equilibrium level would last for several years before convergence between the two finally happens.
Given the estimate of the error-correction coefficient for group 3 of 20.37, it would take two years to reduce the difference between the short- and long-run responses by a half, and another 3 years to cut it by $90 \%$.

There seems to be a variety of dynamic adjustment patterns across countries. The estimates for the group 3 countries (except Canada) do not show too wide a gap between short-run and long-run changes in migrant flows as a result of our scenario; therefore, small dynamics can be observed there despite relatively slow speed of adjustment. Quick adjustment in the countries of groups 2 and 4 enables them to get back to the equilibrium path promptly. On the other hand, there are countries with a sizeable shortto long-run impact gap and a modest speed of adjustment, such as those in groups 1 (Continental Europe) and 5 (Northern Europe) and Canada. These would experience a long process of downward adjustment of the current immigration to its "promised' level, during which speculations may be heard of the alleged failure of the two to converge.

However, significance of the error-correction coefficients implies that convergence to equilibrium of the 
Table 3. Simulation results

\begin{tabular}{|c|c|c|c|c|c|c|c|}
\hline \multirow[b]{2}{*}{ Group } & \multirow[b]{2}{*}{ Country } & \multicolumn{2}{|c|}{ Joint impact, group wide } & \multicolumn{4}{|c|}{ Joint impact, country specific } \\
\hline & & Short run & Long run & Short run & SD & Long run & SD \\
\hline \multirow{7}{*}{1} & Austria & \multirow{7}{*}{0.830} & \multirow{7}{*}{0.208} & 0.616 & 0.130 & 0.158 & 0.134 \\
\hline & Belgium & & & 0.610 & 0.148 & 0.254 & 0.130 \\
\hline & France & & & 0.803 & 0.174 & 0.201 & 0.144 \\
\hline & Germany & & & 0.823 & 0.183 & 0.201 & 0.143 \\
\hline & Luxembourg & & & 1.063 & 0.277 & 0.406 & 0.274 \\
\hline & Netherlands & & & 1.190 & 0.328 & 0.247 & 0.162 \\
\hline & Switzerland & & & 0.865 & 0.219 & 0.234 & 0.149 \\
\hline \multirow{4}{*}{2} & Greece & \multirow{4}{*}{1.535} & \multirow{4}{*}{0.151} & 0.355 & 0.461 & 20.353 & 0.300 \\
\hline & Italy & & & 1.755 & 0.397 & 20.057 & 0.228 \\
\hline & Portugal & & & 0.842 & 0.480 & 0.856 & 0.300 \\
\hline & Spain & & & 1.699 & 0.494 & 0.402 & 0.361 \\
\hline \multirow{5}{*}{3} & Australia & \multirow{5}{*}{0.840} & \multirow{5}{*}{0.725} & 1.118 & 0.238 & 1.184 & 0.239 \\
\hline & Canada & & & 1.112 & 0.234 & 0.299 & 0.299 \\
\hline & Ireland & & & 1.430 & 0.331 & 1.147 & 0.370 \\
\hline & UK & & & 0.864 & 0.197 & 0.686 & 0.254 \\
\hline & US & & & 0.779 & 0.161 & 0.742 & 0.169 \\
\hline \multirow{4}{*}{4} & Japan & \multirow{4}{*}{6.235} & \multirow{4}{*}{1.202} & 4.820 & 0.516 & 0.749 & 0.388 \\
\hline & Korea & & & 9.790 & 1.615 & 2.303 & 1.344 \\
\hline & Singapore & & & 9.006 & 0.877 & 2.520 & 0.457 \\
\hline & Denmark & & & 1.309 & 0.322 & 0.341 & 0.210 \\
\hline \multirow[t]{3}{*}{5} & Finland & \multirow{3}{*}{1.193} & \multirow{3}{*}{0.491} & 1.501 & 0.370 & 0.818 & 0.373 \\
\hline & Norway & & & 0.938 & 0.208 & 0.428 & 0.224 \\
\hline & Sweden & & & 1.073 & 0.254 & 0.423 & 0.211 \\
\hline
\end{tabular}

Notes: Impacts significant at $10 \%$ are highlighted in bold.SDs of the joint impacts are calculated based on statistical simulation of a sample of 10000 observations of a random variable modelled as the sum of individual impacts, given their individual SDs and their covariation matrix obtained from previous regressions estimations.

net migration rate does take place. It is the relatively slow speed of adjustment and large gap between the short- and long-run levels of net migration rate that together create the illusion of the actual immigration persistently 'overshooting' its predicted level.

\section{Conclusion}

The dynamic approach implemented in this study shows differences in response of migration to its determinants in the short and long-run. There is a tendency for the short-run migration response to 'overshoot' compared to its level sustainable in the long-run. Therefore, policy makers in a destination country should expect some short-run excess of the actual migration over its predicted level.

\section{References}

Camarota, S. (2004) Economy slowed, but immigration didn't. The foreign born population, 20002004. Backgrounder, November 2004. Available from the
Center for Immigration Studies web site, at http:// www.cis.org/articles/2004/back1204.pdf

Clark, X., Hatton, T. J. and Williamson, J. G. (2002) Where do U.S. immigrants come from and why?, NBER Working Paper No. 8998.

Fertig, M. (2001) The economic impact of EU enlargement: assessing the migration potential, Empirical Economics, 26, 70720.

Hatton, T. J. (1995) A model of UK emigration, 1870 1913, The Review of Economics and Statistics, $77,40715$.

Hatton, T. J. and Williamson, J. G. (1998) The Age of Mass Migration: Causes and Economic Impact, Oxford University Press, New York.

Hatton, T. J. and Williamson, J. G. (2002) What fundamentals drive world migration?, NBER Working Paper No. 9159.

Hatton, T. J. and Williamson, J. G. (2003) Demographic and economic pressure on emigration out of Africa, Scandinavian Journal of Economics, 105, 46586.

Mayda, A. M. (2004) International migration: a panel data analysis of economic and non economic determi nants, Unpublished paper available at http:// www.georgetown.edu/faculty/amm223/International Migration0304.pdf

Pedersen, P., Pytlikova, M. and Smith, N. (2004) Selection or network effects? Migration flows into 27 
OECD Countries, 1990 2000, IZA Discussion Paper No. 1104.

Rotte, R. and Vogler, M. (1998) Determinants of interna tional migration: empirical evidence for migration from developing countries to Germany, IZA Discussion Paper No. 12.
Sjaastad, L. A. (1962) The costs and returns of human migration, Journal of Political Economy, 70, 8093.

Statistical Office of the European Communities (Eurostat) (2004) Population Statistics, Office for Official Publications of the European Communities, Luxembourg. 